\title{
ACNE VULGARIS - ADEQUATE AND TIMELY THERAPY AS AN EARLY PREVENTION OF PSYCHOSOCIAL DISTURBANCES
}

\author{
Mirjana Paravina ${ }^{1}$, Milica Stepanović ${ }^{2}$, Predrag Štilet ${ }^{3}$, Danica Janjić Spasić ${ }^{3}$ \\ ${ }^{1}$ Faculty of Medicine University of Niš, Niš, Serbia \\ ${ }^{2}$ Special Hospital for Rehabilitation "Prolom Banja", Prolom Banja, Serbia \\ ${ }^{3}$ Private Surgery Predrag Štilet, Tivat, Montenegro
}

\begin{abstract}
Acne is a polyetiological chronic disease of pilosebaceous units that affects $80 \%$ to $90 \%$ of teenagers and adolescents. It is manifested as mild, moderate, or severe form. Since adolescence is time of psychological, emotional and social personality development, the appearance of acne, most frequently on face, demands long-term treatment, significantly affects psychologic and emotional state, creating the feeling of being marked and leading to depression, anxiety, social isolation and negative effect on the quality of life. Timely education, with general information on the causes, duration of the disease and adequate treatment can significantly affect patients' relation to the disease and reduction of psycho-social problems. The analysis included 220, 39 (55\%) males and 60 (45\%) females, 14 to 30 years of age (or more), most frequently 16 to 20 years old with moderate form of the disease. Therapy was applied according to valid protocols. Each patient was given full attention with the explanation of the nature and course of the disease. The largest number of patients had the expected results, which was mutually appreciated. It was concluded that individual approach and cooperation during the treatment of each patient were necessary.
\end{abstract}

Key words: Acne vulgaris, therapy, psychosocial disturbances, quality of life.

\section{Introduction}

Acne is a polyetiological chronic disease of pilosebaceous units. The etiopathogenesis involves the following: 1. elevated sebum production stimulated by the effects of androgynous hormone, 2. elevated follicular proliferation and keratinocyte differentiation, 3. colonization of Propionibacterium acnes, 4. inflammation induction. Acnes are manifested as: mild form (A. comedonica), moderate (A. papulosis and A. nodules-small nodule), and as a severe form (nodulo-cystica and A. conglobata). The presence of acne (most frequently on face, chest and back) demands long-term treatment. It has been estimated that $80-90 \%$ of teenagers and adolescents suffer from acne, although they can be present during adulthood as well $[1,2]$. Adolescence is the period of psychic, emotional and social personality development $[3,4]$. Acnes strongly affect $[5,6]$ psychological and emotional wellbeing, creating the self-image and the feeling of being marked, which leads to frustration, anger, depression, anxiety, social isolation, life-long problems with confidence and self-respect, with higher unemployment rate, limited choice of work place, inability of promotion, inappropriate comments. As a result, negative effect on the quality of life of the patient is registered.

Correspondence to: Mirjana Paravina, MD, Ph.D.

18000 Niš, 40/3Majakovskog Str., 18000 Niš, Serbia

E-mail: mirjanaparavina@gmail.com

Phone: +381642009804

Received April 27 $7^{\text {th }}, 2018$, Accepted December 20 ${ }^{\text {th }}, 2018$

\section{The Aim}

The aim is the analysis of patients treated for acne (gender, age, disease type, applied therapy, treatment success).

\section{Materials and Methods}

The analysis included 220 outpatients. Therapy was applied according to the valid protocol: topical retinoids (keratinocyte proliferation, inflammation), oral retinoids (sebum production, keratinocyte proliferation, Propionibacterium acnes colonization, inflammation), azelaic acid (keratinocyte proliferation, $P$. acnes colonization and inflammation), topical and oral antibiotics (P acnes colonization and inflammation), benzoyl peroxide (sebum production, keratinocyte proliferation, $P$. acnes colonization), hormones (sebum production) and alpha HA and beta HA (keratinocyte proliferation). Each patient was given a detailed explanation of the nature of their disease, its mechanism of appearance, duration, therapeutic possibilities, results and their personal contribution to the successful treatment.

\section{Results}

Results are present in tables.

Table 1 presents the structure of treated patients according to gender. Out of 220 treated patients, 87 were male $(39.55 \%)$ and $133(60.45 \%)$ were female. 
Table 1 Gender structure

\begin{tabular}{lrrr}
\hline Gender & Male & Female & \multicolumn{1}{c}{ Total } \\
\hline Number & 87 & 133 & 220 \\
Percentage & 39.55 & 60.45 & 100.00 \\
\hline
\end{tabular}

Table 2 Age structure

\begin{tabular}{lrrrrrr}
\hline Age & Up to 15 & $16-20$ & $21-25$ & $26-30$ & Over 30 & Total \\
\hline Number & 30 & 109 & 55 & 17 & 9 & 220 \\
Percentage & 13.64 & 49.54 & 25.00 & 7.73 & 4.09 & 100.00 \\
\hline
\end{tabular}

Table 3 Type of the disease

\begin{tabular}{lccccrr}
\hline Form & Mild & Moderate & \multicolumn{2}{c}{ Serious } & \multirow{2}{*}{ Total } \\
\hline Type & $\begin{array}{c}\text { Type I } \\
\text { A. comedonica }\end{array}$ & $\begin{array}{c}\text { Type II A. } \\
\text { papulopustulosa }\end{array}$ & $\begin{array}{c}\text { Type III } \\
\text { A. nodularis }\end{array}$ & $\begin{array}{c}\text { Type IV } \\
\text { A. nodulocystica }\end{array}$ & $\begin{array}{c}\text { Type IV } \\
\text { A. conglobata }\end{array}$ \\
\hline Number & 33 & 91 & 61 & 24 & 11 & 220 \\
Percent. & 15.00 & 41.36 & 27.73 & 10.91 & 5.00 & 100.00 \\
\hline Total/\% & 15.00 & 69.09 & & 15.91 & & 100.00 \\
\hline
\end{tabular}

Table 4 Gender structure of the isotretinoin treated patients

\begin{tabular}{lrrr}
\hline Gender & Male & Female & \multicolumn{1}{c}{ Total } \\
\hline Number & 13 & 3 & 16 \\
Percentage & 81.25 & 18.75 & 100.00 \\
\hline
\end{tabular}

Table 5 Age structure of the isotretinoin treated patients

\begin{tabular}{lrrrr}
\hline Age & Up to 15 & $16-20$ & $21-25$ & Total \\
\hline Number & 3 & 9 & 4 & 16 \\
Percentage & 18.75 & 56.25 & 25.00 & 100.00 \\
\hline
\end{tabular}

Table 6 Type of acnes in isotretinoin treated patients

\begin{tabular}{lcccr}
\hline Form & Moderate & Serious & Total \\
\cline { 2 - 4 } & Type II & Type IV & Type IV & \\
\hline Number & A. papulopustulosa & A. nodulocystica & A. conglobata & 16 \\
Percentage & 1 & 7 & 8 & 100.00 \\
\hline Total/\% & 6.25 & 43.75 & 50.00 & 100.00 \\
\hline
\end{tabular}

Table 2 presents the age structure of the treated patients. The majority of the treated patients was in the age group of 16-20 years $(109-49.54 \%)$, then $21-25$ years $(55-25.00 \%)$ and to 15 years $(30-13.64 \%)$, with reduced numbers for $26-30$ years $(17-7.73 \%)$ and over 30 $(9-4.09 \%)$.

Table 3 presents the disease structure according to types depending on intensity. Most frequently it was Moderate, type II - Acne papulopustulosa (91 - 41.36\%) and type III - Acne nodularis $(61-27.73 \%)$, total 152 $69.09 \%$. Mild form (type I - Acne comedonica) was present in $33-15.00 \%$ of the treated patients. Serious forms: Acne nodulocystica (type IV) had $24-10.91 \%$ of the treated, and Acne conglobata (Type IV) $11-5.00 \%$, total of $35-15.91 \%$ of the treated patients.

Table 4 shows the structure according to gender of those treated with isotretinoin. Out of 16 treated 13 patients $(81.25 \%)$ were male and $3(18.75 \%)$ were female.

Table 5 shows the age structure of the patients treated with isotretinoin. The majority, 9 patients $(56.25 \%)$ was in the category of $16-20$ years, then $4-24 \%$ from $21-25$ years and $3-18,75 \%$ up to 15 years.

Table 6 presents the disease structure according to types depending on intensity. Moderate form -Type II, Acne papulopustulosa was found in 1 patient $(6.25 \%)$. Serious forms - Type IV, Acne nodulocystica were found in 7 patients $(43.75 \%)$ and Acne conglobata was present in 8 patients $(50.00 \%)$, total $15(93,75 \%)$ patients.

Great majority of patients had the expected results (figures) which was mutually appreciated. Figures: 1A, 2A,
3A (at the beginning of treatment); 1B (After one month), 2B (After 2 months), 3B (4 months after the treatment with isotretinoin).
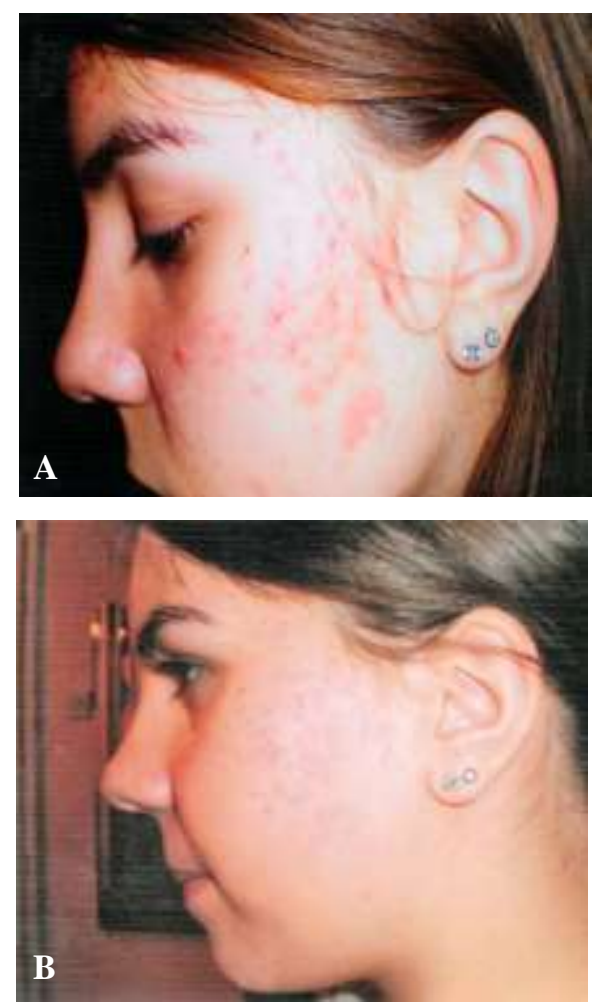

Fig. 1 A - At the beginning of the treatment, B - after one month 

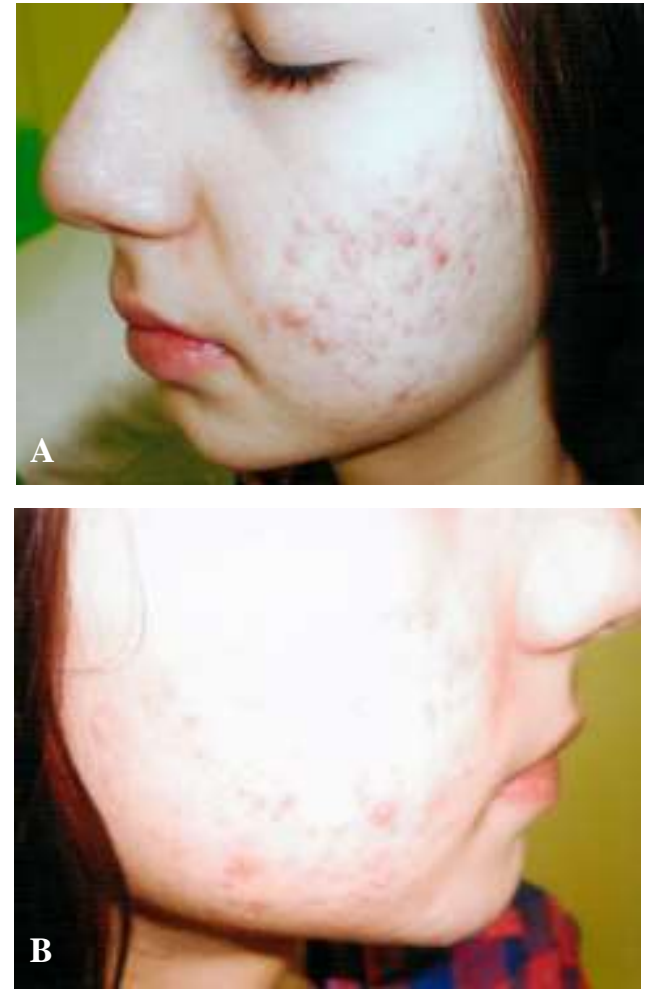

Fig. $2 \mathrm{~A}$ - At the beginning of the treatment, B - After 2 months
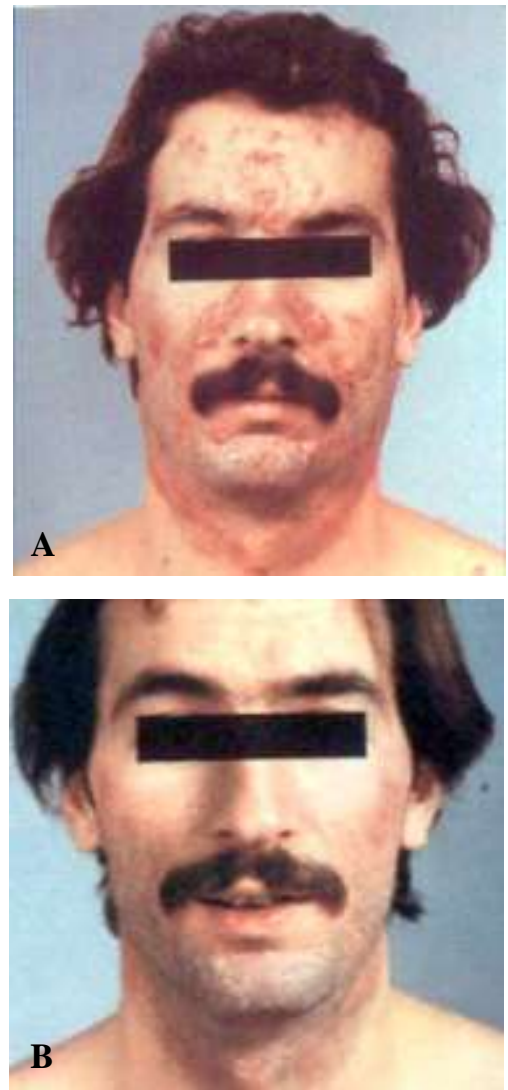

Fig. 3 A - Before the treatment, B - 4 months after the treatment with isotretinoin

\section{Discussion}

The treatment was conducted with 220 patients aged between 15 to 35 . The largest number of patients was in the category of 16 to 20 years of age $(49.54 \%)$. There were more female patients ( $\mathrm{f}: \mathrm{m}=60,45 \%: 39,55 \%$ ). The greatest number had a moderate form $(69.9 \%)$. All the patients had full attention during the treatment and there was also an attempt to affect their behavior and acceptance of the reality with the aim of overcoming the present discomfort.

"There is no other disease which provokes so much psychological trauma, and lack of possibility to improve the relationship between parents and children, so much insecurity and inferiority feeling and so much psychological suffering as acne vulgaris" [7]. Social and economic effects of acne are usually related to a high prevalence of this pathology, which can be marked as a public health problem [8]. More than 2000 studies on the relationship between acne and psychological state of the patients were performed [9]. Emotional problems as well as behavioral ones are determined as double in those affected with acne [10]. Significantly elevated stress level in relationships with other people and in everyday life is evident [11]. People affected with acne have lower level of self-confidence and higher level of depression and anxiety [9]. Higher level of dissatisfaction is registered in persons with facial acne [12]. Clinically significant anxiety was registered in $44 \%$ of the affected, while clinically significant depression was registered in 18\% [13]. Age, sex and seriousness of acne are closely related to depression [14]. The prevalence of acne grows with age, in girls when they get period. In moderate acne, the higher level of psychic symptoms is more frequent in later periods of puberty [15]. The prevalence of anxiety in the affected is $68.3 \%$. Anxiety and depression rates were not related to the age, sex, marital status and the acne SCOR [16]. Suicidal ideas are not rare in dermatology patients and they can occur in patients with mild skin lesions, as well [17].

The highest prevalence of suicidal ideas is found in psoriasis patients $(7.2 \%)$, acne $(5.6 \%)$, atopic dermatitis $(2.1 \%)$, and in none with alopecia areata [18].

The prevalence of suicidal ideas in the patients with acne is $8 \%$ [19] and 7\% [17]. Some patients became suicidal even after successful dearmabrasion [20]. The suspicion that isotretinoin used for acne treatment, could provoke depression and suicidal ideas, is not supported by scientific evidence. Acnes are the primary cause of depression and efficient treatment can improve the depression symptoms and reduce the frequency of suicidal ideas [21]. The lack of serious acne treatment with isotretinoin is accompanied with a higher risk for suicide [22]. Stress is a leading factor in the appearance of a large number of chronic non-infectious diseases [23]. It seems that stress causes acne and that acnes cause stress. There is a vicious stress-acne circle [24]. The correlation between the perceived stress and the seriousness of clinical picture of papulopustular acne is 
proven. The combination of treatment for acne and controlling stress affects both causes and helps the diseased. Anxiety prevention in adolescence means prevention of many mental disorders later in life [25]. Not only that it is evident that acnes are a visual condition which can provoke various psychosocial effects, but also that mental health problems provoke acne or make them worse [26]. However, the impact of acne on psychological implications of their treatment has not been fully understood, they are often considered to be a cosmetic temporary problem [12]. Considering acne as a cosmetic problem and neglecting psychosocial aspect can be dangerous $[27,28]$. It is important to concentrate on the subjective perception of acne treatment without regard to the objective seriousness [11]. The reduction of psychological effects of acne is considered to be one of the leading priciples for their clinical treatment [29].

Timely education with general information on the causes and duration of the disease and early intervention accompanied with adequate treatment, probably psychotherapy and anti-anxiety drugs, can significantly affect patients' attitude towards the disease as well as avoidance and reduction of the psychosocial problems. The quality of life of the patients with acne is on the same level as that in patients with other chronic conditions (asthma, diabetes, epilepsy, arthritis) [30]. Acnes are accompanied with the disturbed quality of life of the affected [31[. Acnes negatively affect the quality of life [32]. In most students the quality of life is moderately harmed [33]. Only $17 \%$ of boys and $18 \%$ of girls perceive their problems with acne as huge. $15 \%$ of students felt depressed and miserable due to their acne [34]. Moderate disturbance of the quality of life was found regardless of sex, while it was worse in the case of a

\section{References}

1. Pawin H, Chivot M, Beylot C, et al. Living with acne. A study of adolescents personal experiences Dermatology 2007; 215(4): 308-314.

2. Krowchuck DP. Managing acne in adolescents. Ped Clin North Am 2000; 47(4):66-70.

3. Feton- Danou N. Psychological impact of acne vulgaris. Ann Dermatol Venereol 2010; 137:S62-65.

4. Hassan J, Grogan S, Clark-Carter D, Richards H, Yates VM. The individual health burden of acne: appearance-related distress in male and female adolescents and adults with back, chrest and facial acne. J Healt Psychol 2009; 14:1105-1118.

5. Dunn LK, O'Neill JL, Feldman SR. Acne in adolescents: quality of life, self-esteem, mood, and psychological disorders. Dermatol Online 2011; 17:1.

6. Bowe WP, Leyden JJ, Crerand CE, Sarwer DB, Margolis Dj. Body dysmorphic disorder symptoms among patients with acne vulgaris. J Am Acad Dermatol 2007; 57:222-230.

7. Sulzberger MB, Zaidens SH. Psychogenic factors in dermatological disorders. Med Clin North Am 1948; 32:669-672.

8. Semyonov L. Acne as public health problem It J Publ Health 2010; 7(2):112-114.

9. Ryder K. The Physical and Emotional Distres of Acne. Doc Slyde 2006.

10. Smithard A, Glazebroppk C, Williams HC. Acne - prevalence, knowledge about acne and psychological morbidity in midadolescence: a community - based study. Br J Dermatol 2001; 145(2):274-279. prolonged disease [35]. The effect of acnes on the quality of life of adolescents is more pronounced in serious clinical forms of acnes, more obvious in women [36]. The disease provokes higher psychosocial disturbance in women [37]. The quality of life depends on the degree of the disease as well as on its duration, although in people affected with mild forms of the disease and shorter duration the effect on the quality of life is also registered [38]. It is believed that there is a linear relationship between the clinical seriousness of acne and the quality of life [39]. However, the condition depends on the capability of a person to cope and sometimes persons with mild acnes can have serious subjective symptoms, which affects their quality of life [40]. Acnes can greatly affect patients' lives, regardless of how serious they are [27].

Efficient treatment of acne in combination with appropriate mental health support offers great opportunity for the improvement of the quality of life of people with acne [30].

\section{Conclusion}

Individual approach is necessary in the treatment of each patient, with the awareness of etiopathogenesis of the disease and wide array of drugs, with necessary psychotherapy accompanied with the information about the nature and the duration of the disease and the possibility of gaining good results, following necessary cooperation and discipline.

Note: This paper was presented at The First Regional Congress on The Health of the Young, Belgrade 2016.

11. Do JE, Cho SM, In SI, Nim KY, Lee S, Lee ES. Psychosocial Aspects of Acne Vulgaris: A Community-based Study with Korean Adolescents. Ann Dermatol 2009; 21(2):125-129.

12. Isaacsson VCS, de Almeida HL, Jr, Duquia RP, Breunig JA, de Souza PRM. Dissatisfaction and acne vulgaris in male adolescents and associated factors. Ann Bras dermatol 201489(4).

13. Kellett SC, Gawkrodger DJ. The psychological and emotional impact of acne and the effect of treatment with isotretinoin. Br J Dermatol 1999; 140:273-282.

14. Al Huzali SMAS, Al-Malki KS, Al-Nikhali SAS, Al-Matrafi KAM. Prevalence of depression among acne patients in King Faisal Hospital and King Abulaziz Hospital in Makkah, Saudi Arabia. Int J Med Sci Publ Health 2014; 3(9):1150-1156.

15. Kilkenny M. Stathakis V, Hibbert ME, Patton G, Caust J, Bowes G. J Peditr Child Health 1997; 33(5):430-433.

16. Gollchal J, Khani SH, Heidarzadeh A, Eshkevari SS, Alizade $\mathrm{N}$, Eftekhari $\mathrm{H}$. Comparison of anxiety and derpression in patients with acne vulgaris and healthy individuals. Indian $\mathbf{J}$ Dermatol 2010; 55(4):352-354.

17. Picardi A, Mazzotti E, Pasquini P. Prevalence and correlates of suicidal ideation among patients with skin disease. JAm Acad Dermatol 2006; 54(3):420-426.

18. Gupta MA, Gupta AK. Depression and suicidal ideation in dermatology patients with acne, alopecia areata, atopic dermatitis and psoriasis. Br J Dermatol 1998; 139:846-850.

19. Khan MZ, Naeem A, Mufti KA. Prevalence of mental health problems. J Ayub Med Coll Abbottabad 2001; 13:7-8. 
20. Gieler U. Psychosomatische Aspecteder Akne. Hautarzt 1988; 39:117-118.

21. Hull Pr, D'Arci C. Acne, depression, and suicide. Dermatol Clin 2005; 23(4):665-674.

22. Sundstrom A. Assotiation of suicide attempts with acne and treatment with isotretinoin: retrospective Swedish cohort study. Br Med J 2010: 341:c5812.

23. Petrović Tadić XXXV Dani Prev Med, Zbornik radova Niš 2001.

24. Rivera R. How anxiety and panic attacks cause acne problems and how to deal with it. Calm Clin Comp 2013

25. Jovanović G, Prvi kongres pedijatara SR Jugoslavije, Zbornik radova 1994.

26. Halvorsen JA. Is the association between acne and mental distress influenced by diet? Results from a cross-sectional population study among 3775 late adolescents in Oslo, Norway. BMC Public Health 2009; 9:340. doi: 10.1186/1471-2458-9-340.

27. Koo J. The psychosocial impact of acne: patiens perception. J Am Acad Dermatol 1995; 32:S26-S30.

28. Niemeier V, Kupfer J, Geler U. Acne is not a trivial disease!. Psychosomatic aspects in routine therapy. Dermatol Psychosom 2002; 3:61-70.

29. Berson DS, Chalker DK, Harper JC, Leyden JJ, Scalita AR, Webster GF. Current concepts in the treatmant of acne: report from a clinical round table. Cutis 2003; 72(1 Suppl):5-13.

30. Mallon E, Newton JN, Klassen A, Stewart-Brown SL, Ryan TJ, Finaly AY. The quality of life in acne: a comparison with general medical condition using generic questionnaires. $\mathrm{Br} \mathrm{J}$ Dermatol 1999; 140: 672-676.
31. Reljić V, Maksimović N, Janković J, Mijović B, Perič J, Janković S. Evaluation of the quality of life in adolescents with acne. Vojnosanit Pregl 2014; 71(7): 634-638.

32. Green L. The effect of skin condition on patient, quality of life. Nurs Stand 2010; 25:48-55.

33. Perić J, Maksimović N, Janković J, Mijović B, Reljić V, Janković S.Vojnosanit Pregl 2013; 70(10):935-939.

34. Jankovć S, Vukicevic J, Djordjević S, Janković J, Marinković J. Quality of life among school children with acne. Results of a cross-sectional study. Ind J Dermatol Venereol Leprol 2012; 78(4): 454-458.

35. Đorđević S. Procena kvaliteta života kod srednjoškolaca obolelih od akni. Magistarska teza Beograd 2010

36. Kurtalić N, Hadžigrahić N. Procena kvaliteta života adolescenata sa aknama vulgaris u odnosu na težinu kliničke slike i spol. www.pedijatrija danas.com 2010.

37. Shahzad N, Nasir J, Ikram U, Asmaa-ul-Haque, Qadir A, Sohail MA. Frequency and psychosocial impact of akne on university and college students. J Coll Physic Surg Pak 2011; 21(7): 442-443.

38. Petrović M, Spalević Lj, Ljubenović M. Kvalitet života bolesnika sa aknama. VI BDD Beograd Zbornik radova 1999: 45-47.

39. Fried Rg. Acne Vulgaris: The psychosocial and psychological burden of illness. The Dematologist 2013;28-32. https://pdfs. semanticscholar.org/a3e7/11d0e64f6fbbc52d4388537ce0aa00d2ee 65.pdf?_ga=2.237448774.794284743.1570769864-705254304. 1567999979

40. Walker N, Lewis-Jones MS. Quality of lifeand acne in Scottish adolescent schoochildren: use of the Children, s Dermatology Life Quality Index (CDLQI) and the Cardif Acne Disability Index (CADI). J Eur Acad Dermatol Venereol 2006; 20(1): 45-50. 